\title{
Mosquito repellent activity of cotton functionalized with inclusion complexes of $\beta$-cyclodextrin citrate and essential oils
}

\author{
Shelly Khanna and J. N. Chakraborty * (1)
}

*Correspondence:

chakrabortyjn@hotmail.com

National Institute

of Technology,

Jalandhar 144011, India

\begin{abstract}
With the progress of time, demand for healthy and hygienic clothing has gone up tremendously. Fabrics and apparels finished with mosquito repellent finishes belong to one of such highly looked out clothing's. The present study aims at synthesis, characterization and optimization of $\beta$-Cyclodextrin citrate ( $\beta$-CD CA) followed by its complexion with essential oils of cedarwood, clove, eucalyptus, peppermint, lavender and jasmine for the assessment of repellent efficacy against Anopheles Stephensi by means of arm in cage assays on cotton. Protection time, repellency (\%), biting (\%) and mortality (\%) of inclusion complexes encapsulated with oils were evaluated. Two way ANOVA and post hoc analysis had affirmed the significant effect of essential oil type on bio-assay. Lavender and cedarwood had provided the longest protection times (210 and $160 \mathrm{~min}$ respectively); jasmine and peppermint were least effective showing protection times of 20 and 60 min whereas oils of eucalyptus and clove behaved as feeding deterrents. Peppermint and lavender were effective as potential repellents and cedarwood had shown supreme mortality against arthropods. Jasmine was the weakest repellent due to its flower-nectar stimulating upshot for Anopheles stephensi.
\end{abstract}

Keywords: $\beta$-cyclodextrin citrate, Repellent efficacy, Anopheles stephensi, Protection time, \% mortality, Inclusion complexes, Bio-assay, Feeding deterrents

\section{Introduction}

Due to the increased awareness about health and hygiene, people increasingly demand their clothing to be hygienically afresh and functional as market has been expanded for specialty clothing (Karolia and Mendapara 2005). Mosquito repellence with the use of textiles is a promising area of functionality. Many species of mosquitoes are the vectors of numerous fatal diseases, with no effective vaccines against the ailments caused by them. Personal protection is one of the approaches to prevent mosquito bites. The only way to avoid the disorders is to keep away from the mosquito bites. Mosquito repellent textiles are one of the revolutionary ways to advance the textile field by providing immensely needed features of driving away the mosquitoes. It protects the human beings from the bite of mosquitoes, and thereby promising safety from the mosquito borne diseases such as malaria, dengue fever, chicken guinea and filarial (Prabha and Vasugi 2012). Both natural as well as synthetic repellents are exploited against mosquitoes. But

(C) The Author(s) 2018. This article is distributed under the terms of the Creative Commons Attribution 4.0 International License (http://creativecommons.org/licenses/by/4.0/), which permits unrestricted use, distribution, and reproduction in any medium, provided you give appropriate credit to the original author(s) and the source, provide a link to the Creative Commons license, and indicate if changes were made. 
natural repellents as essential oils are the upcoming genre of scientific interest due to their non-toxic, non-sticky, non-irritating and eco-friendly nature; however, essential oil repellents tend to being short-lived in their effectiveness due to their high volatility and requirement of frequent re-application. This problem has been tried to be overcome with the controlled release of oils from the textiles using monomolecular inclusion complexes with $\beta$-cyclodextrin ( $\beta$-CD) in native form (Songkro et al. 2012), $\beta$-CD with crosslinking agents as polycarboxylic acids namely citric acid, BTCA, acrylic acid (Martel et al. 2002a, b; Voncina and Marechal 2005; El-Tahlawy et al. 2007; Specos et al. 2013), MCT $\beta$-CD (Hebeish et al. 2008; Romi et al. 2005; Abdel-Mohdy et al. 2008, 2009; Shahba et al. 2011; Hebeish et al. 2009, 2010) on varied substrates. The use of citric acid as crosslinking agent for $\beta$-CD had been extensively reported for cotton for diversified functionalities (Aly et al. 2004; Fahmy 2004; Martel et al. 2002b; Ramchandran 2009; Dehbadi et al. 2014; Kasprzyk et al. 2010; Fouda and Fahmy 2011) but the use of $\beta$-CD CA as a host for mosquito repellent finishing has been worked and cited scarcely (Samanta et al. 2016). Also, the process parameters for attachment of $\beta$-CD CA on textile substrates as individual parameters during reaction has been reported, that too rarely without any emphasis on their interactions (Martel et al. 2002b; El-Tahlawy et al. 2006; Ramchandran 2009). As the reactivity of citric acid towards cellulose is higher than that towards $\beta-C D$, results in different desired reaction conditions of citric acid towards cellulose and $\beta-C D$, necessitated the requirement of a two-step procedure. (Martel et al. 2002b).

Thus, the aim of present work was the synthesis, characterization, optimization of a novel modified cyclodextrin host $(\beta-\mathrm{CD} C \mathrm{CA})$ for inclusion complexation with essential oils and its application on cotton for adjudgement of potential of inclusion complexes against malaria causing arthropods scientifically.

\section{Methods}

\section{Materials}

Thoroughly pre-treated plain woven cotton fabric possessing epi (76), ppi (70), warp $\left(42.8 \mathrm{Ne}^{\mathrm{s}}\right)$, weft $\left(38 \mathrm{Ne}^{\mathrm{s}}\right.$ ) and gsm (136), six categories of essential oils (Eos)- clove (CO), cedarwood (CdO), eucalyptus (EO), peppermint (PO), lavender (LO) and Jasmine (JO) were used. All the analytical grade chemicals, viz. $\beta$-cyclodextrin $(\beta-C D)$, citric acid (CA), sodium hypophosphite (SHP), ethanol and Isopropanol were supplied by SDFL, Mumbai. FTIR-spectroscope (Perkin Elmer, US), Bruker Avance II NMR Spectrometer (Saif, PU, Chandigarh, India), Thermogravemetric Analyser (SDT Q600 V20.9 Build 20; NITRA, Gaziabad, India), Water bath (Laboratory glassware Co.), Padding mangle (Electronic \& Engg. Company), Electronic weighing balance (CAS Model MW-11 series), Drying oven (Kaypee Udyog, India), Soxhlet, freeze drier, Laundrometer (RBE), Tensile tester (Globe Tex Industries) and Computer colour matching (Macbeth colour-eye) were the equipment used to evaluate the physical properties of the functionalized cotton. Arm in cage/cloth cage was used for the assessment of bio-assay of mosquito repellence.

\section{Synthesis and characterization of $\beta$-cyclodextrin citrate ( $\beta-C D C A)$}

The synthesis of $\beta$-CD CA was carried out according to the procedure described previously by (El-Tahlawy et al. 2006) without any major process modifications using $\beta-C D$, 
CA and SHP in molar ratios 1:2:2. FTIR, TGA and ${ }^{1} \mathrm{H}-\mathrm{NMR}$ (for resonances of protons for structural confirmation) were used for the characterization of synthesized $\beta$-CD CA.

\section{Solubility analysis of $\beta-C D C A$ in water and ethanol}

The solubility of $\beta$-CD CA was analyzed in water and ethanol for the assessment of modification of modified $\beta-C D$ according to Eq. 1.

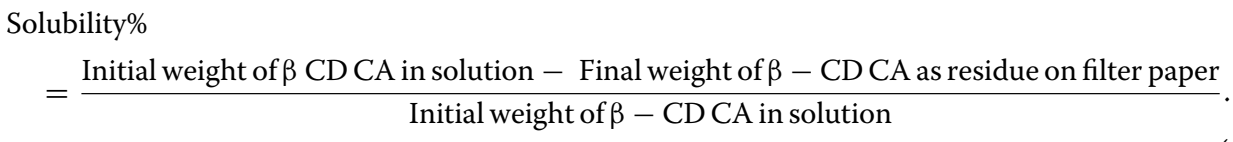

\section{Optimization of process parameters of $\beta-C D C A$ attachment on cotton}

The optimization of process variables for $\beta$-CD CA attachment on cotton was accomplished with response surface methodology using $3^{3}$ Box and Behnken factorial design. $\beta$-CD CA concentration (60, 70, $80 \mathrm{gpl})$, Time of curing $(4,6,8 \mathrm{~min})$ and Temperature of curing $\left(100,130,160{ }^{\circ} \mathrm{C}\right)$ were taken as three independent variables for the assessment of independent responses viz. \% Graft yield, \% change in Tensile strength, \% change in yellowness index and Wash durability (up to 5 washes) of functionalized cotton. The attachment of modified host on cotton was affirmed by FTIR and TGA. Design Expert software version 7.1.2 (State-ease Inc., Minneapolis, USA) was used for statistical analysis and model-fitting of responses. \% Graft yield (GY\%) was determined from the gain in weight of cotton due to the attachment of $\beta$-CD CA after the removal of unattached host according to Eq. 2. Tensile strength was determined according to the ASTM D5034-1995 using digital tensile strength tester. Wash durability was evaluated as \% retained weight gain after washing as- $\beta$-CD CA treated cotton samples were washed according to ISO 105-C03:1989 with $5 \mathrm{gpl}$ of soap and $3 \mathrm{gpl}$ of $\mathrm{Na}_{2} \mathrm{CO}_{3}$, with a M:L 1:50 followed by laundering $60 \pm 2{ }^{\circ} \mathrm{C}$ for $30 \mathrm{~min}$. Rinsing with tap water for $10 \mathrm{~min}$ and drying at room temperature after each wash cycle was done. Yellowness Index was used to determine the degree to which a cotton sample's colour shifts away from an ideal white using Macbeth color eye matching system with D65 illuminant (AATCC test method 110-2000). FTIR was further used to adjudge the presence of $\beta$-CD CA on cotton after 5 washings.

$$
\text { Weight gain }(\%)=\left(\mathrm{W}_{\mathrm{f}}-\mathrm{W}_{\mathrm{i}}\right) / \mathrm{W}_{\mathrm{i}} \times 100
$$

where $\mathrm{W}_{\mathrm{f}}$ and $\mathrm{W}_{\mathrm{i}}$ represent final and initial fabric weight respectively.

\section{Synthesis, characterization and application of inclusion complexes of $\beta$-CD CA-Eos on cotton}

${ }^{1} \mathrm{H}-\mathrm{NMR}$ was used for the determination of stoichiometry and binding constants between $\beta$-CD CA-Eos in solution state with Job's plot (or continuous variation method) and Scott's method (y-reciprocal plot). For this, two stock solutions of $\beta$-CD CA and oil both having $10 \mathrm{mM}$ concentration were prepared. Based on these two equimolar solutions, a series of 5 sample solutionusing magnetic stirrer at $4000 \mathrm{rpm}$ for 25 mins were prepared containing both the oil and host at constant volume with varying proportions, so that a wide range $(0<\mathrm{r}<1)$ of the ratio $\mathrm{r}=[\mathrm{X}] /([\mathrm{H}]+[\mathrm{G}])$ was sampled, where $\mathrm{X}=\mathrm{G}$ or $\mathrm{H}$ and $[\mathrm{H}]$ and $[\mathrm{G}]$ are the total concentrations of the $\beta$-CD CA and oil to achieve 
the total concentration $[\mathrm{H}]+[\mathrm{G}]=[\mathrm{M}]=10 \mathrm{mM}$ i.e. $\{(2.8 \mathrm{mM}),(4.6 \mathrm{mM}),(5.5 \mathrm{mM})$, (6.4 $\mathrm{mM}),(8.2 \mathrm{mM})\}$ with dry mixing technique using magnetic stirrer at $4000 \mathrm{rpm}$ for $25 \mathrm{~min}$ to achieve a uniform and stable complex. The chemical shift $\Delta \delta$ was measured and plotted as a function of ' $r$ ' for Job's plot. The Scott's method (or y-reciprocal plot) was used to investigate the extent of the intermolecular binding as a constant between oils and $\beta$-CD CA according to the Eq. 3. The synthesis of inclusion complexes (ICs) of $\beta$-CD CA-Eos with the optimized $\beta$-CD CA concentration (from the previous section) and oils at 14,16 and $18 \mu \mathrm{L} / \mathrm{cm}^{2}$ (v/v of $100 \%$ ethanol) was carried out by dry mixing followed by freeze drying the complex using freeze drier (at $-22{ }^{\circ} \mathrm{C}$ for $12 \mathrm{~h} ;+20^{\circ} \mathrm{C}$ for next $8 \mathrm{~h}$ and at $30{ }^{\circ} \mathrm{C}$ for $6 \mathrm{~h}$ ). The freeze dried fine powder was applied on cotton at optimized conditions of curing time and temperature. TGA were carried out for the anchorage of ICs on cotton.

$$
\frac{[O I L]}{\Delta \delta_{o b s}}=\frac{[O I L]}{\Delta \delta_{c}}+\frac{1}{K_{a} \times \Delta \delta_{c}}
$$

where, [OIL] molar concentration of oils $(\mathrm{mM}), \Delta \delta_{\text {obs }}$ chemical shift difference observed for MCT $\beta$-CD proton resonances for a given oil concentration, $\Delta \delta_{c}$ difference in chemical shift between the complexed and free MCT $\beta-C D$ at saturation, $K_{a}$ binding constant.

\section{Repellence assessment-arm-in cage bioassay}

Mosquito repellence activity was assessed with the test cage described as "Laboratory testing of non-commercial mosquito repellent formulations on skin employing laboratory reared mosquitoes" (ASTM-E951-83; Jantan and Zaki 1999; Masetti and Maini $2006)$ in cage $\left(30 * 30 * 30 \mathrm{~cm}^{3}\right)$ with an aspirator tube. Laboratory bred and reared 5-10 days old female Anopheles stephensi mosquitoes were used. Adults were fed with $10 \%$ sucrose solution prior to testing and were starved by providing them only water for $15 \mathrm{~h}$. Around 150 adult female mosquitoes were taken to conduct a single bioassay test, 100 of which were exposed to the ICs treated cotton (in 4 replicates of around 25 mosquitoes). The remaining 50 were used for control in 2 replicates (WHO 2013). Bio-assay was determined with-

$$
\begin{aligned}
\text { Protection time }(\mathrm{PT}) & =\text { Time elapsed between application of oil and second successive bite } \\
\% \text { Repellency }(\% \mathrm{R}) & =(\mathrm{C}-\mathrm{T}) / \mathrm{C} \times 100
\end{aligned}
$$

where, $\mathrm{C}$ is the number of biting or landing on the control, $\mathrm{T}$ is number of biting or landing on the treated area calculated at the end of each test.

$\%$ Mortality $(\% \mathrm{M})=$ No. of mosquitoes dead/Total number of mosquitoes in the cage $* 100)$

$\%$ Biting/landing $(\% \mathrm{~B})=\mathrm{B}$ or L/Total number of mosquitoes in the cage $* 100$,

where, $\mathrm{B} / \mathrm{L}$ is the total number of biting or landings at the end of each test.

Cotton samples $\left(650 \mathrm{~cm}^{2}\right.$ area $)$ were treated with ICs and draped over the top of the left forearm. A rubber glove was worn to cover the hand and wrist. Right arm with ethanol treated cotton was taken as a reference. An initial 3 min exposure period was observed for mosquito behaviour followed by observations after every $10,20,30,40$, 
$50 \mathrm{~min}, 1 \mathrm{~h}$ and after that a small $3 \mathrm{~min}$ interval for every $30 \mathrm{~min}$ up to $6 \mathrm{~h}$. Mortality was noted after $24 \mathrm{~h}, \% \mathrm{~B}$ and \% R were noted after $6 \mathrm{~h}$ observation period.

\section{Statistical analysis}

Two-way ANOVA was used to assess the effect of all Eos type and concentrations (14, 16 and $18 \mu \mathrm{L} / \mathrm{cm}^{2}$ ) on the bio-assay. One way analysis of variance followed by TukeyKramer post hoc analysis was used to compare the bio-assay for six oils at $18 \mu \mathrm{L} / \mathrm{cm}^{2}$ concentration. A value of $p \leq 0.05$ was considered statistically significant.

\section{Result and discussions}

\section{Synthesis and characterization of $\beta-C D C A$}

The \% yield of synthesis was satisfactory at 63.96 with DS of $\beta$-CD CA of $0.28-0.42$ and MW at 1310 . The reaction proceeds by the formation of a reactive cyclic anhydride intermediate by the dehydration of two adjacent carboxyl groups under curing conditions for the substitution of the primary hydroxyl groups of $\beta$-CDs with the elimination of water. The reaction mechanism for $\beta$-CD CA synthesis is depicted in Scheme 1. FTIR had shown the presence of the strong absorption band at $3308 \mathrm{~cm}^{-1}$ as compared to 3388 and $3296 \mathrm{~cm}^{-1}$ in $\beta-C D$ and $3445 \mathrm{~cm}^{-1}$ in citric acid assigned to $\mathrm{O}-\mathrm{H}$ stretching. The characteristic peaks of $2931 \mathrm{~cm}^{-1}$ in $\beta-C D, 3284 \mathrm{~cm}^{-1}$ in $C A$ and $2928 \mathrm{~cm}^{-1}$ in $\beta-\mathrm{CD} C A$ are related to $\mathrm{C}-\mathrm{O}$ and $\mathrm{C}-\mathrm{H}$ stretching were detected. An additional extended absorption peak at $1715 \mathrm{~cm}^{-1}$ was observed in $\beta$-CD CA and in CA at $1695 \mathrm{~cm}^{-1}$ (absent in $\beta-C D$ ) attributed to $C=O$ stretching of citrate moieties in $C A$ and $\beta-C D C A$. Further, both $\beta$-CD and $\beta$-CD CA had shown the evidence of carbon in cyclic rings at 1029 and $1020 \mathrm{~cm}^{-1}$ as shown in Fig. 1a. $\beta$-CD CA had shown thermal decomposition as a measure of $\%$ weight change by $T G A$ with $\mathrm{Tg}=235{ }^{\circ} \mathrm{C}$ and $\mathrm{Tp}=315{ }^{\circ} \mathrm{C}$ (Fig. 1b). ${ }^{1} \mathrm{H}-\mathrm{NMR}$ allows the observation of specific resonances of the various protons located within the cyclodextrin cavity. $\mathrm{H} 3$ and $\mathrm{H} 5$ atoms are located in the interior cavity; $\mathrm{H} 1, \mathrm{H} 2, \mathrm{H} 4$ and H6 are located on the exterior of the cavity (Levya et al. 2001). H2-H6 are attributed to the cyclodextrin ring whereas, $\mathrm{Ha}$ and $\mathrm{Ha}^{\prime}$ are the chemical shifts of citric acid backbone. The chemical shifts for $\beta$-CD CA are H2 (3.3680), H3 (3.6083), H4 (3.3114), H5 (3.6560), $\mathrm{H6}$ (3.5), $\mathrm{Ha}(2.5167)$ and $\mathrm{Ha}^{\prime}(2.5688 \mathrm{ppm})$.

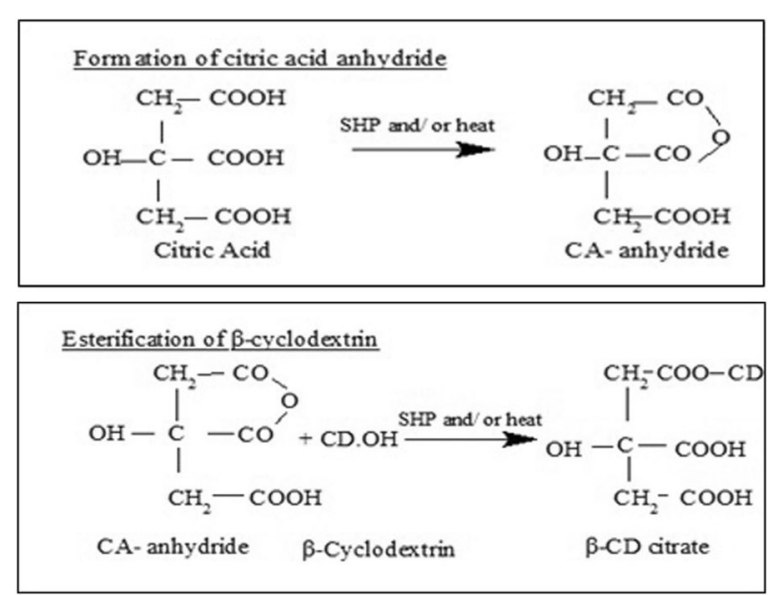

Scheme1 Stepwise reaction mechanism of $\beta-C D C A$ synthesis 

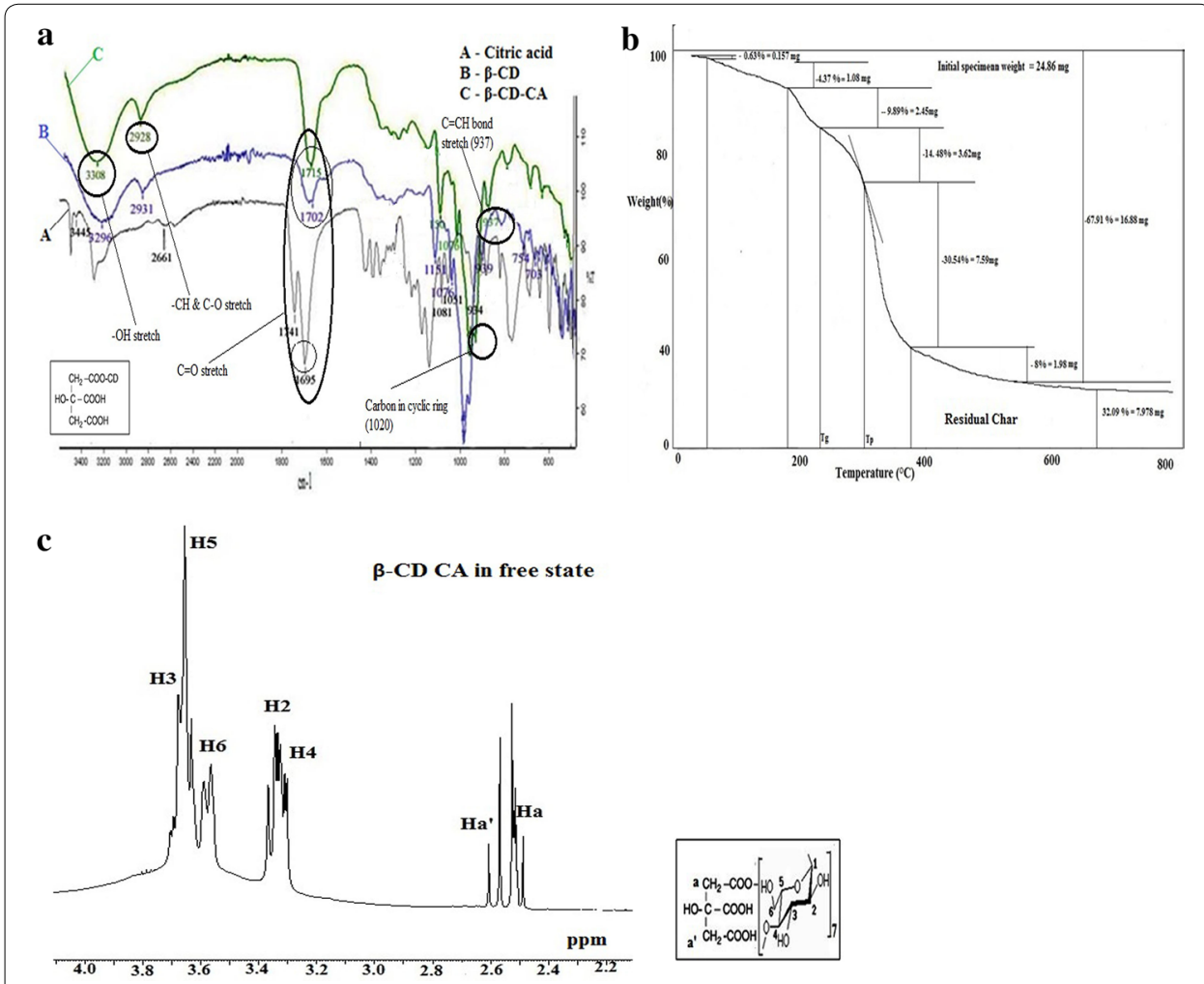

Fig. 1 a Comparative FTIR of citric acid, $\beta-C D$ and $\beta-C D$ CA $\mathbf{b}$ TGA of $\beta-C D$ CA $\mathbf{c}^{1} H-N M R$ of $\beta-C D$ CA

\section{Solubility of $\beta-C D C A$}

The substitution of native $\beta$-CD had increased its solubility in both water and ethanol due to extreme high solubility of CA itself in both media even at very low temperatures. With increase in $\beta$-CD CA concentration in aqueous media, the restriction to the solubility increased due to the increased number of strained cyclodextrin rings. Water was chosen to be used as the working medium. An increase of 51\% (at $60 \mathrm{gpl}$ ) up to $91 \%$ (at $100 \mathrm{gpl}$ ) was found for $\beta$-CD CA as compared to native $\beta$-CD.

\section{Optimization of process parameters of $\beta-C D C A$ attachment on cotton}

The reaction mechanism of $\beta$-CD CA with cellulose can be described as-the two carboxyl groups present in citric acid dehydrate to form a reactive cyclic anhydride that further, reacted with the secondary $-\mathrm{OH}$ groups of $\beta-\mathrm{CD}$ to form $\beta$-CD CA. After this, the remaining carboxyl groups at the end of $\beta-C D C A$ chain might have reacted with the $-\mathrm{OH}$ groups of cellulose. (Dong et al. 2014) as shown in Fig. 2a). FTIR analysis had affirmed the presence of modified host on functionalized cotton with the $\mathrm{C}=\mathrm{O}$ strong ester group at $1742 \mathrm{~cm}^{-1}$, which was not revealed by control as shown in Fig. $\left.2 \mathrm{~b}\right) . T G A$ had shown that the presence of $\beta$-CD CA on cotton due to the reduction of $\mathrm{Tg}$ of control had reduced from $290{ }^{\circ} \mathrm{C}$ up to $248^{\circ} \mathrm{C}$ and Tp had reflected a change from 383 to $365^{\circ} \mathrm{C}$ solely due to the adherence of reactive host ( $\beta$-CD CA) on cotton that had its own $\mathrm{Tg}$ and $\mathrm{Tp}$ at lower temperatures of 235 and $315^{\circ} \mathrm{C}$. 

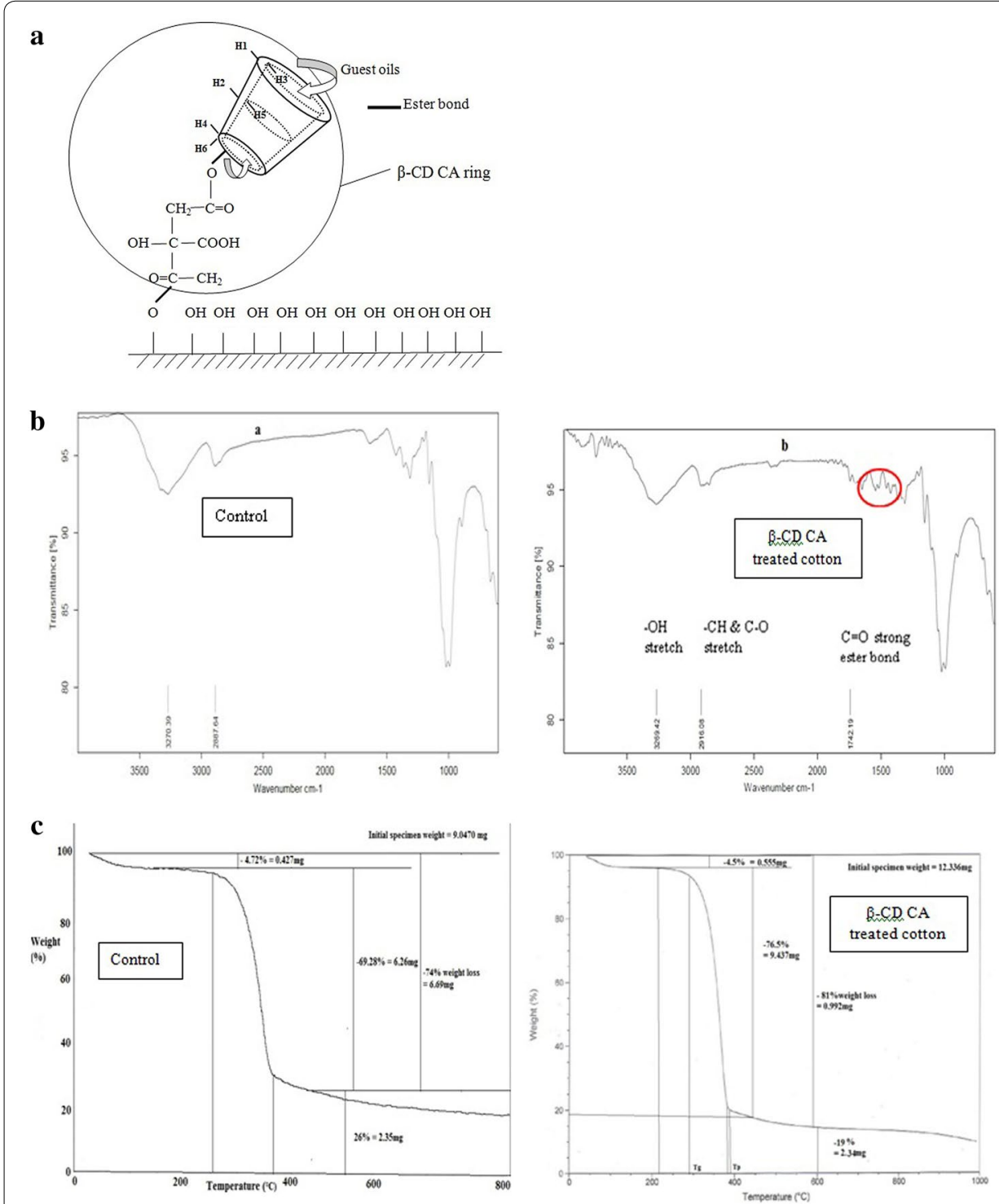

Fig. 2 a Mode of attachment of $\beta-C D$ CA with cellulose $\mathbf{b}$ Comparative FTIR spectra of control and $\beta-C D C A$ treated cotton $\mathbf{c}$ TGA of control and $\beta-C D$ CA treated cotton

A desirability function $(\mathrm{DF})=\mathrm{f}\{\mathrm{GY}, \mathrm{TS}, \mathrm{YI}, \mathrm{WD}\}$ was designed for the optimization of process parameters as-GY\% is \% graft yield targeted to 'maximum, TS is \% loss in tensile strength targeted to 'minimum', YI is \% change in yellowness index targeted to 'minimum' and WD is wash durability of host treated cotton in terms of \% retained weight gain targeted to 'maximum'. The statistical analysis of dependent responses is shown in Tables 1 and 2 .

\section{Graft yield (\%)}

It had shown dependence on $\beta$-CD CA concentration and curing temperature (Fig. 3a). With the increase in concentration and temperature from $\left(60 \mathrm{gpl}\right.$ and $\left.100{ }^{\circ} \mathrm{C}\right)$ to $(80 \mathrm{gpl}$ and $160{ }^{\circ} \mathrm{C}$ ) for $6 \mathrm{~min}$, GY had increased from $5.69 \%$ up to $7.62 \%$ due to the increase in the availability of the $\beta$-CD CA molecules for attachment on cotton as the higher 


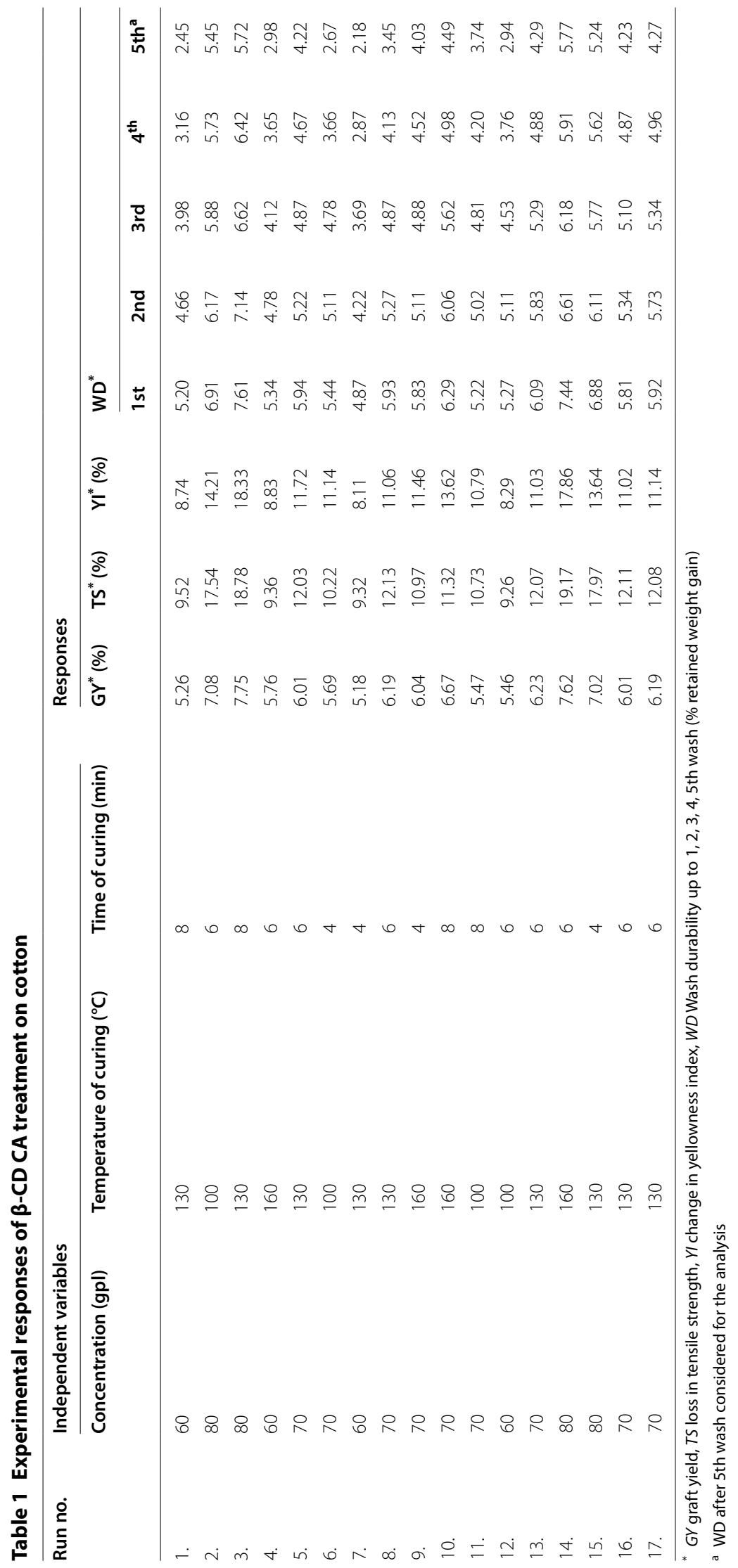


Table 2 Statistical analysis for desirability (Model equations)

\begin{tabular}{|c|c|c|c|c|c|}
\hline Response & Model equations & $\mathrm{R}^{2}$ & Adjusted $\mathrm{R}^{2}$ & Predicted $\mathrm{R}^{2}$ & Lack of fit (Prob $>F)$ \\
\hline Y1, GY\% & $\begin{array}{l}6.13+0.98 X_{1}+0.3 X_{2}+0.15 X_{3}+0.3 \\
\quad 4 X_{1}^{2}-0.17 X_{3}^{2}+0.16 X_{1}^{*} X_{3}\end{array}$ & 0.9773 & 0.9480 & 0.705 & 0.0763; Not significant \\
\hline Y2, TS & $\begin{array}{l}12.08+4.50 X_{1}+0.38 X_{2}+0.23 \\
X_{3}+2.42 X_{1}^{2}-0.67 X_{2}^{2}+1.54 X_{3}^{2} \\
0.15 X_{1}^{*} X_{2}+0.38 X_{1}^{*} X_{3}\end{array}$ & 0.9998 & 0.9996 & 0.998 & 0.068; Not significant \\
\hline Y3, YI & $\begin{array}{l}11.19+3.76 X_{1}+0.92 X_{2}+0.89 X_{3} \\
0.78 X_{1}^{2}+0.33 X_{2}^{2}+0.23 X_{3}^{2} \\
1.01 X_{1}^{* *} X_{2}+0.63 X_{2}^{*} X_{3} \\
+0.68 X_{1}^{*} X_{3}\end{array}$ & 0.9854 & 0.9667 & 0.8038 & 0.0536; Not significant \\
\hline Y4,WD & $4.01+1.45 X_{1}+0.31 X_{2}+0.31 X_{3}$ & 0.9048 & 0.8828 & 0.8271 & 0.4601; Not significant \\
\hline
\end{tabular}

concentration increases the diffusion of $\beta$-CD CA into the vicinity of cellulose fibres. But the use of high temperature might be harmful for the fibre as a result of citrate degradation as shown in Fig. $3 \mathrm{~b}$ ). The interaction of $\beta$-CD CA concentration with curing time had also influenced the grafting ratio as change in the process parameters from $(60 \mathrm{gpl}$ and $4 \mathrm{~min}$ ) up to ( $80 \mathrm{gpl}$ and $8 \mathrm{~min}$ ) at $130^{\circ} \mathrm{C}$ reflected the increase in GY from $5.18 \%$ up to $7.75 \%$ due to the favourable conditions of temperature and time of curing to graft high proportion of host molecules on the cotton (Fig. 3c).

\section{Loss in tensile strength (\%)}

The combined effect of $\beta$-CD CA concentration and curing temperature on TS of functionalized cotton is shown in (Fig. 4a). With the increase in concentration at all the temperatures, there is an increase in TS\% due to the acid-catalysed cellulose depolymerisation and cross linking of cellulosic chains that limited the mobility of the chains to equalize the distribution of stress on individual chains, within the substantial range of $9.26 \%$ at $\left(60 \mathrm{gpl}\right.$ and $\left.100{ }^{\circ} \mathrm{C}\right)$ up to $19.17 \%$ at $\left(80 \mathrm{gpl}\right.$ and $\left.160{ }^{\circ} \mathrm{C}\right)$ for $6 \mathrm{~min}$. TS was

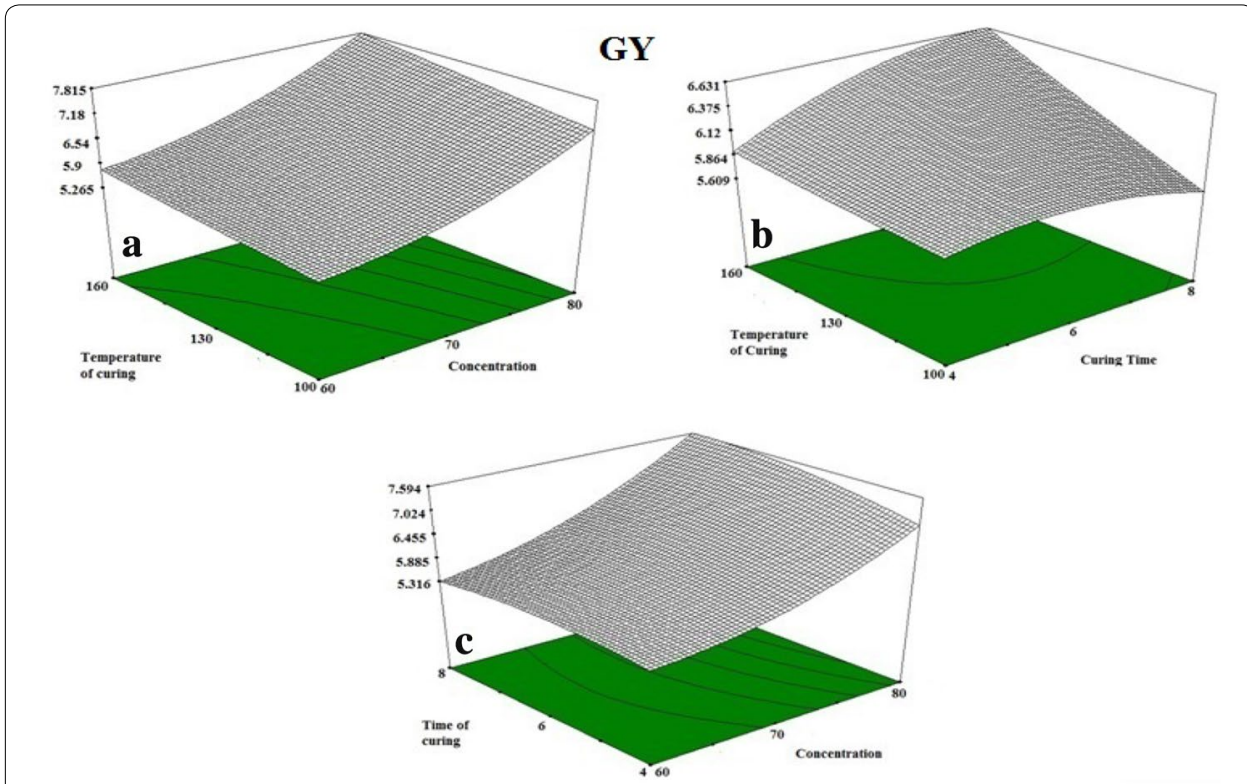

Fig. 3 Effect of process variables on GY\% of treated cotton. a Temperature of curing \& Concentration. $\mathbf{b}$ Temperature of curing \& Curing time. c Time of curing \& Concentration 


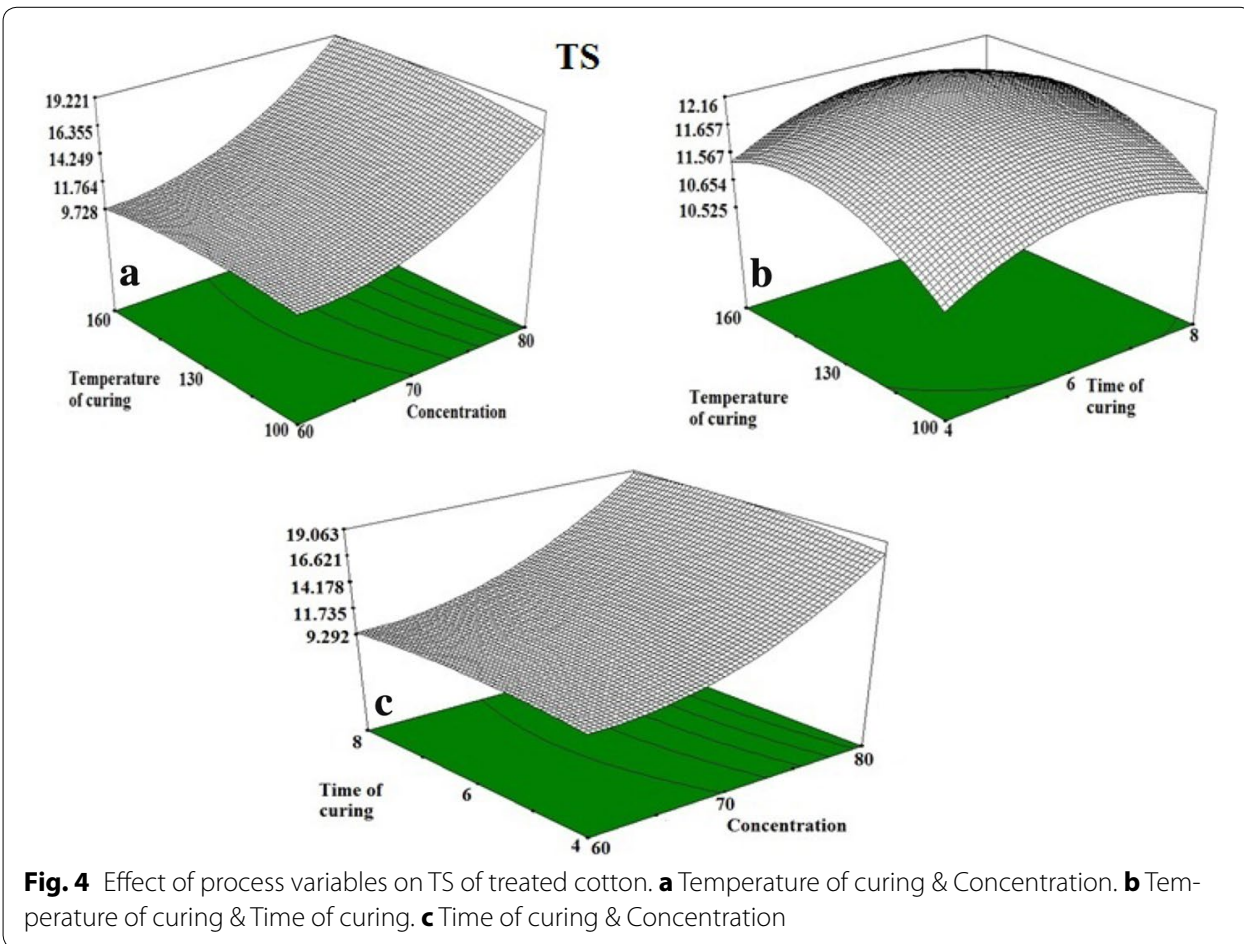

lesser up to $70 \mathrm{gpl}$ but as concentration increased from 70 to $80 \mathrm{gpl}$, TS had increased due to the increased formation of cross links and presence of $\beta$-CD CA on cotton that augmented degradation of treated cotton at the higher temperatures. The effect of curing temperature and time is shown in Fig. 4b). The increase in the levels from (4 min and $\left.100{ }^{\circ} \mathrm{C}\right)$ up to $\left(8 \mathrm{~min}\right.$ and $\left.160^{\circ} \mathrm{C}\right)$ at $70 \mathrm{gpl}$, TS increased at lower level but decreased at their highest levels i.e. TS increased from 10.22 to $12.03 \%$ as the levels increased from the interactions $\left(4 \mathrm{~min}\right.$ and $\left.100{ }^{\circ} \mathrm{C}\right)$ to $\left(6 \mathrm{~min}\right.$ and $130{ }^{\circ} \mathrm{C}$ ) but it fell to $11.32 \%$ at $8 \mathrm{~min}$ and $160{ }^{\circ} \mathrm{C}$, TS lowered down followed by its shooting up at the middle level due to the rapid cross linking of the citrate chains to cotton but as temperature and time both increased, citrate degradation affected TS as no more crosslinking was achieved but with the tenderness of cotton (Fig. 4c).

\section{Change in yellowness index (\%)}

It is evident from Fig. 5a that more the amount of the host on cotton leads to the increase of the yellowness at all levels of curing temperature, i.e. with the increase in the citrate concentration, the yellowness index increased because citrate component of $\beta$-CD CA is known to cause fabric yellowing. The major reason of cotton yellowing in presence of $\beta$-CD CA is the formation of unsaturated cis- and trans-aconitic acids (primarily at higher curing temperatures) prior to the formation of anhydrides through dehydration. The effect of curing temperature at low $\beta$-CD CA concentrations was lesser significant on the yellowness of cotton, whereas, at higher levels of concentration and temperature, the YI changed from $17.86 \%$ from $8.29 \%$. The combined effect of curing time and temperature did not bring a substantial change in YI (Fig. 5b). The interaction of concentration and curing time followed the same trend as with the concentration and temperature on YI (Fig. 5c). 


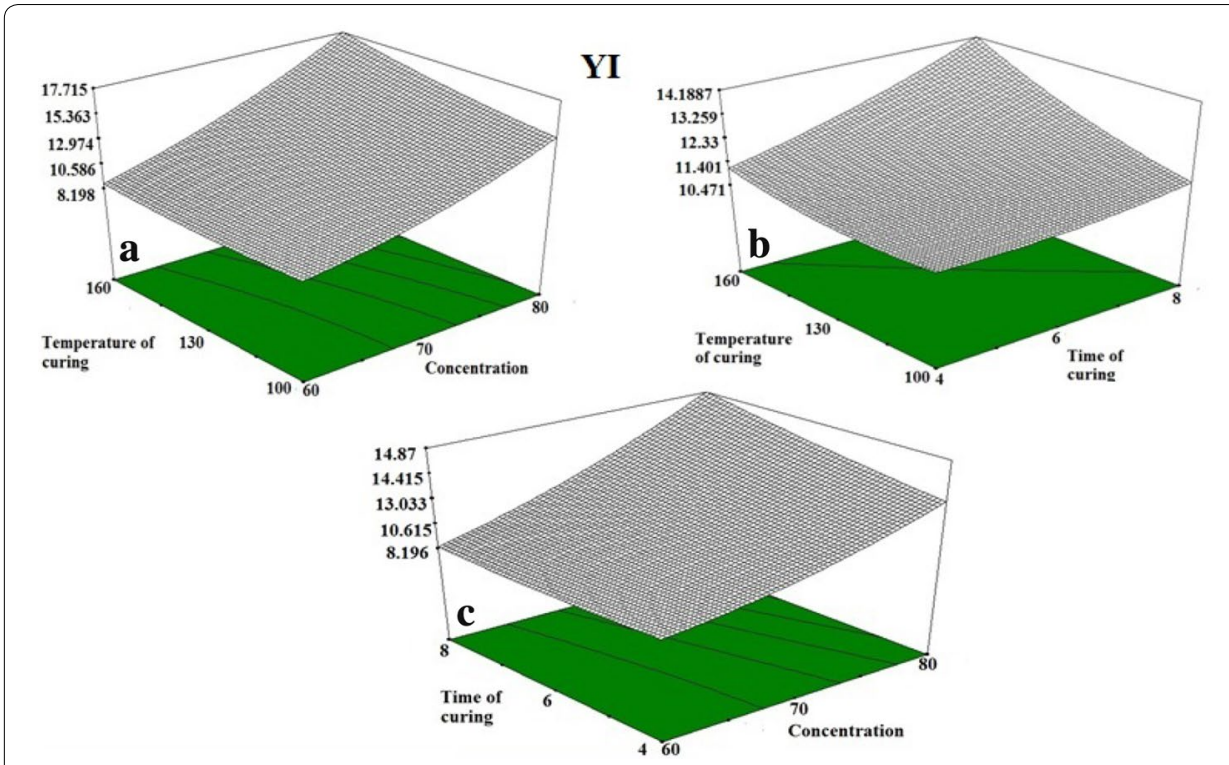

Fig. 5 Effect of process variables on Yl of treated cotton. a Temperature of curing \& Concentration. b Temperature of curing \& Time of curing. c Time of curing \& Concentration

\section{Wash durability}

WD was affected mainly by the concentration of $\beta$-CD CA present on cotton as can be seen in Fig. 6. With the increase in the host concentration from 60 to $80 \mathrm{gpl}$, WD increased after 5 subsequent washes that depended on the amount of citrate host present on cotton, higher the amount of the $\beta$-CD CA molecules in the vicinity of the cellulose, greater is the grafting ratio.

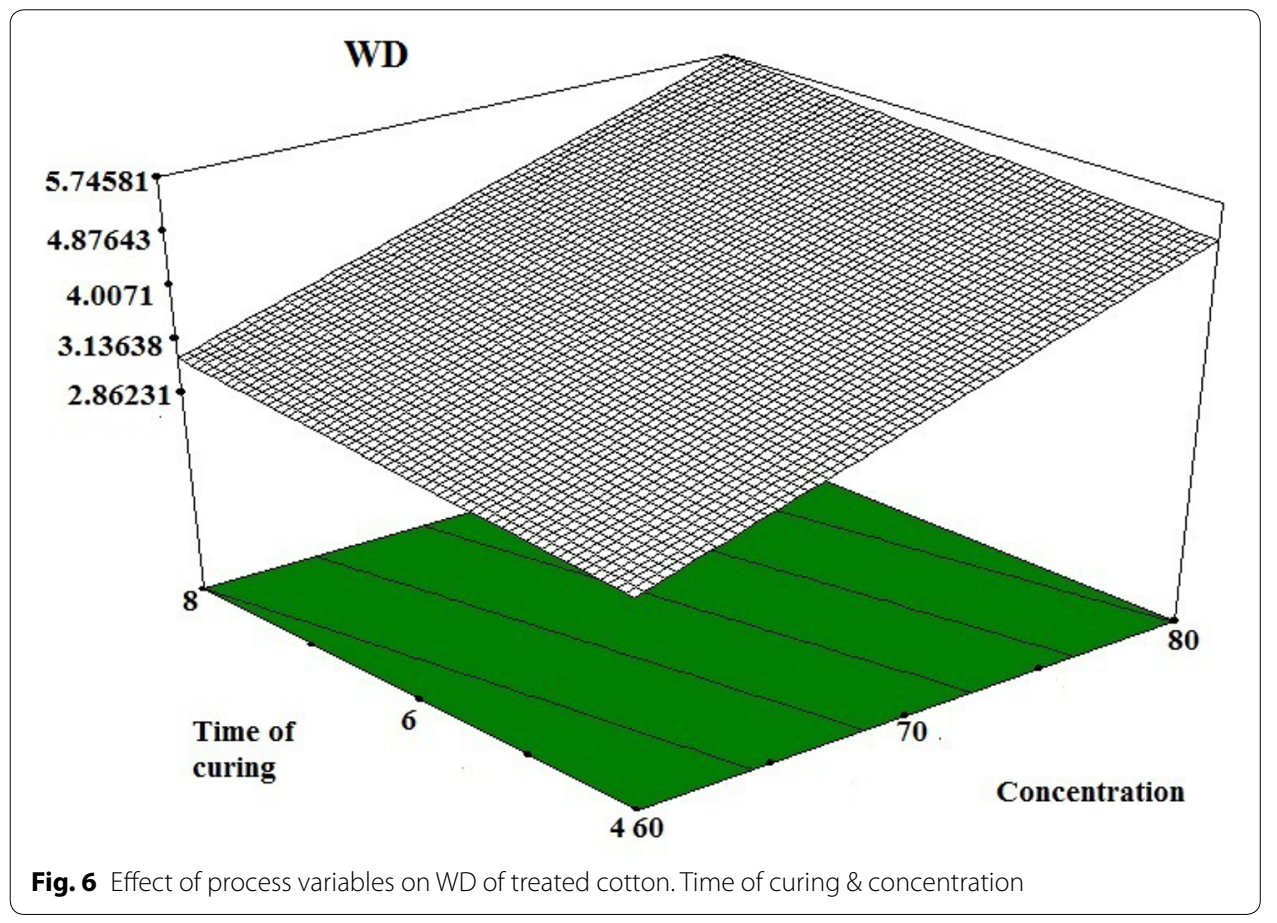


The optimized variables for attachment of $\beta$-CD CA on cotton were $63.46 \mathrm{gpl}$ (concentration), $160^{\circ} \mathrm{C}$ (curing temperature) and $7.15 \mathrm{~min}$ (curing time) having experimental validation of $R^{2}=0.987$. FTIR spectra had revealed the presence of ester linkage intact even after 5 subsequent wash treatments as in unwashed functionalized cotton (Fig. 7).

\section{Synthesis, characterization and application of ICs of $\beta$-CD CA-Eos on cotton}

The Job's plot had demonstrated that $\Delta \delta \beta-\mathrm{CD} C A$ ('H' resonance) was maximum at ' $r$ ' $=0.5$ and highly symmetrical shape depicting the complexes of all Eos-host had 1:1 stoichiometry (Fig. 8a) and binding constants between oils- $\beta-C D$ CA were given by Scott's plot as shown in Table 3 and Fig. 8b). Also, the direction and extent of penetration of Eos into the cavity was also determined with ${ }^{1} \mathrm{H}$-NMR spectra (Fig. 8c). The trend of binding constant of Eos with host was CO- $\beta-C D C A<L O-\beta-C D C A<C d O-\beta-C D$ $C A<$ EO- $\beta-C D C A<$ PO- $\beta-C D C A<$ JO- $\beta-C D$ CA. For EO, partial penetration of the oil molecules from the tail side into the wider rim was observed. $\mathrm{PO}$ had been observed with the possibility of inclusion of the oil from either side of the chain and from both sides of cavity. LO was enclosed into the cavity from either of the rims through tail side. Entry of $\mathrm{CO}$ could be from either of the two sides of the chain via wider opening of the cavity but the possibility of complexation from the tail side is more due to the non-polar nature of the functional groups present in this part of the chain. CdO was entrapped partially into the cavity from either of the two sides but penetration of oil from the head side of chain is more probable due to its lesser polar nature than the other side. JO had shown full inclusion into the cavity from both rims from the tail side. Also, it was observed that all Eos were partially entrapped into the cavity except JO that was fully trapped into the cavity.

A comparative TGA of $\beta$-CD CA, control, $\beta$-CD CA treated cotton and IC functionalized cotton is shown in Fig. 9. It can be inferred that $\mathrm{Tp}$ of control at $383^{\circ} \mathrm{C}$ was shifted to $365{ }^{\circ} \mathrm{C}$ after treatment with $\beta$-CD CA, that further reduced to $355^{\circ} \mathrm{C}$ when treated

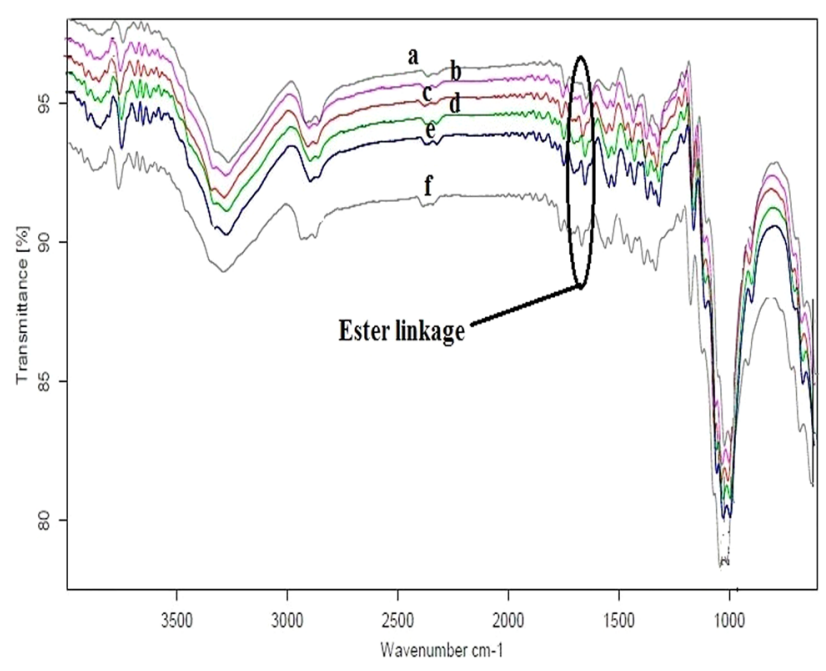

Fig. 7 FTIR analysis of a) $\beta-C D$ CA treated cotton after 1st wash b) $\beta$-CD CA treated cotton after 2 nd wash c) $\beta$-CD CA treated cotton after 3rd wash d) $\beta$-CD CA treated cotton after 4th wash e) $\beta-C D C A$ treated cotton after 5 th wash $f$ ) $\beta$-CD CA treated cotton (without wash) 

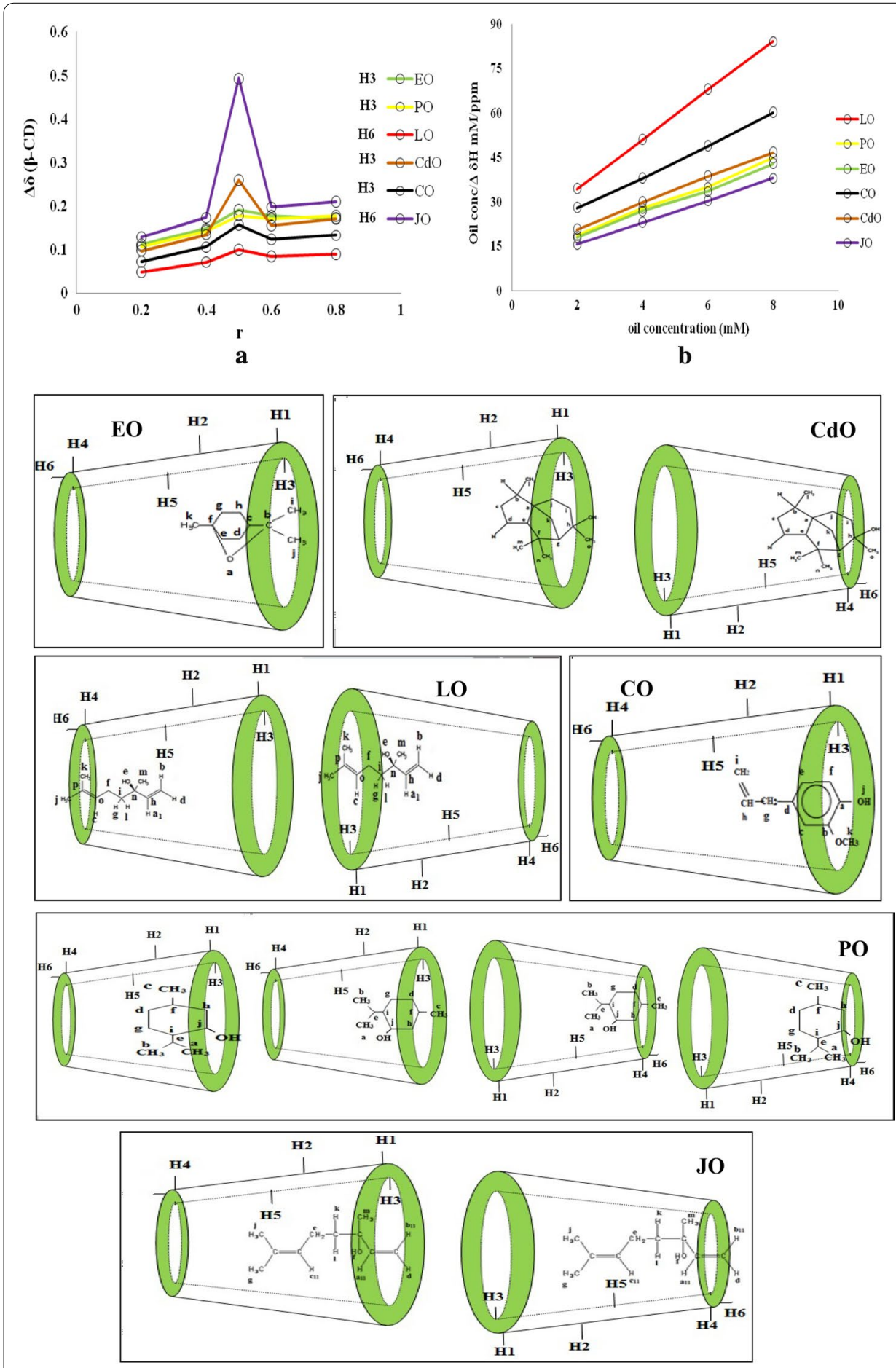

Fig. 8 a Job's plot of host-guest complexes at varying 'r'. b Scott's Plot for Eos: $\beta-C D$ CA ICs with $r=0.5$ (1:1). c Behavior of Eos within the $\beta-C D$ CA cavity

with host-oil complexes. The char residue also had shown a substantial change from $19 \%$ (control), 26\% ( $\beta$-CD CA treated cotton) and further, 29\% (for complex treated cotton). This change was observed because of the presence of IC, from which evaporation of oil 
Table $3{ }^{1} \mathrm{H}-\mathrm{NMR}$ data of oil conc/ $\Delta \delta \mathrm{H}$ for binding constants between ICs of Eos $\& \beta$-CD CA

\begin{tabular}{|c|c|c|c|c|c|c|}
\hline \multirow{2}{*}{$\begin{array}{l}\text { Oil conc. } \\
\text { (mM) }\end{array}$} & \multicolumn{6}{|l|}{ Oil conc./ $\Delta \delta \mathrm{H}$} \\
\hline & EO (H3) & $\mathrm{PO}(\mathrm{H} 3)$ & LO (H6) & $\mathrm{CdO}(\mathrm{H} 3)$ & $\mathrm{CO}(\mathrm{H} 3)$ & JO (H6) \\
\hline 2 & 17.99 & 18.74 & 34.39 & 20.72 & 27.98 & 15.67 \\
\hline 4 & 26.99 & 27.92 & 50.91 & 29.9 & 37.96 & 23.07 \\
\hline 6 & 33.61 & 34.98 & 67.98 & 38.62 & 48.79 & 30.39 \\
\hline 8 & 42.87 & 44.96 & 84.17 & 46.64 & 60.12 & 38.13 \\
\hline $\begin{array}{l}\text { Y-recip- } \\
\text { rocal } \\
\text { equa- } \\
\text { tion }\end{array}$ & $4.063 x+10.05$ & $4.286 x+10.22$ & $7.920 x+24.76$ & $4.324 x+12.35$ & $5.362 x+16.9$ & $3.735 x+8.14$ \\
\hline$R^{2}$ & 0.996 & 0.996 & 0.997 & 0.999 & 0.996 & 0.999 \\
\hline $\begin{array}{c}\text { Binding } \\
\text { con- } \\
\text { stant } \\
\left(\mathrm{M}^{-1}\right)\end{array}$ & 404 & 419 & 319 & 350 & 317 & 460 \\
\hline
\end{tabular}

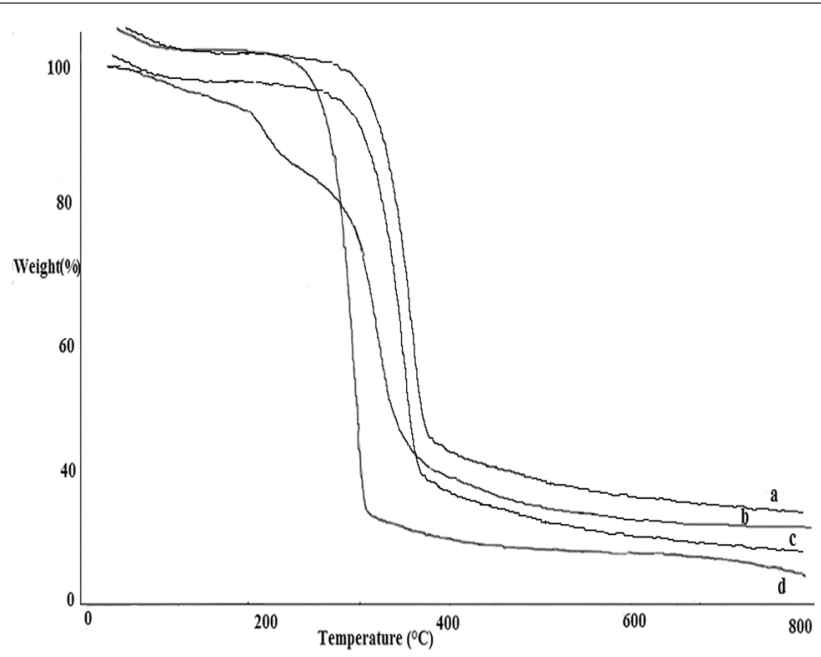

Fig. 9 TGA (a) Cotton treated with IC of $\beta-C D C A(70 \mathrm{gpl})$ : Oil (10\%) (b) $\beta-C D C A(70 \mathrm{gpl})$ (c) $\beta$-CD CA treated cotton (d) control

had taken place, followed by the decomposition of $\beta$-CD CA and cellulose. Further, ICs of $\beta$-CD CA-Eos were synthesized for application on cotton at $63.46 \mathrm{gpl}$ host and 14, 16 and $18 \mu \mathrm{L} / \mathrm{cm}^{2}$ Eos. The freeze dried ICs were applied on cotton via pad, dry and cure at $160{ }^{\circ} \mathrm{C}$ and for $7.15 \mathrm{~min}$.

\section{Repellence assessment-arm-in cage bioassay}

\section{Statistical analysis}

Eo type had a significant effect on the bio-assay. PT with $\{\mathrm{F}(5,17)=3.3, p<0.05\}$, \% $\mathrm{R}$ with $\{\mathrm{F}(5,17)=3.3, p<0.05\}$, \% B with $\{\mathrm{F}(5,17)=3.3, p<0.05\}$ and $\% \mathrm{M}$ with $\{\mathrm{F}(5,17)=3.3, p<0.05\}$ had confirmed that the bio-assay of all Eos was significantly different from each other. The effect of oil concentrations on the repellent activity was significantly different for $\% \mathrm{M}\{\mathrm{F}(2,17)=4.1, p=0.02\}$ and $\% \mathrm{R}=\{\mathrm{F}(2,17)=4.1$, $p=0.005\}$, but not for $\% \mathrm{~B}\{\mathrm{~F}((2,17)=4.1, p=0.14\}$ and $\mathrm{PT}=\{\mathrm{F}(2,17)=4.1, p=0.98\}$. 
The one-way ANOVA showed a significant effect of the factor Eo $(F(5,23)=144$.4; $\mathrm{p}<0.05)$. Mean comparisons had shown that $\% M$ of all Eos except $\mathrm{CO}(44 \%)$ and $\mathrm{EO}$ (40\%) was statistically significant. \% $R$ for $\mathrm{CdO}(48.5 \%)$ and $\mathrm{CO}(51.5 \%), \mathrm{CO}(51.5 \%)$ and LO (55\%), EO (60\%) and PO (64\%) and EO (60\%) and LO (55\%) were not significantly different than the other Eos groups. \% B for CdO (39\%) and CO (37\%), LO (35\%) and $\mathrm{CdO}(39 \%), \mathrm{CO}(37 \%)$ and $\mathrm{LO}(35 \%)$ and EO (30\%) and PO (27\%) was insignificant than other Eos (Table 4).

The repellent activity of Eos against Anopheles Stephensi mosquitoes is shown in Table 5 and Fig. 10. During the initial 3 min exposure, only JO and control had shown mosquito landing. In the 1st $\mathrm{h}$ of exposure of treated cotton, other than $\mathrm{JO}$ and control; $\mathrm{PO}$ and EO also had shown few mosquito bites $(2 \mathrm{~B}$ and $1 \mathrm{~B})$ due to the reason that PO was the one with the lowest \% release from the IC functionalized cotton that wasn't able to ward the mosquitoes away from the cotton's surface. But, EO was released to a considerably greater extent; even then it had allowed the bites. The bio-assay for the IC treated cotton followed the following pattern-Mean PT (minutes): $\mathrm{JO}<\mathrm{PO}<\mathrm{EO}<\mathrm{CO}$ $<$ CdO $<$ LOMean \% R: $\mathrm{JO}<\mathrm{CdO}<\mathrm{CO}<\mathrm{LO}<$ EO $<$ POMean \% $\mathrm{M}$ : $\mathrm{JO}<\mathrm{LO}<\mathrm{PO}<$ EO $<\mathrm{CO}<$ CdOMean \% $\mathrm{B}$ : $\mathrm{JO}>\mathrm{CdO}>\mathrm{CO}>\mathrm{LO}>\mathrm{EO}>\mathrm{PO}$

$P T$-LO had shown the longest PT and JO was with the least PT due to the fastest \% release of LO and slowest for JO from IC. EO and CO gave shorter PTs due to their deterrent behavior against mosquito biting and landing. PO had low PT due to its slower $\%$ release initially, which wasn't able to retard mosquitoes from landing and biting. \% $B$ and $\% R-\mathrm{JO}$ and $\mathrm{CdO}$ had shown poor $\% \mathrm{~B}$ and \%R, due to lowest \% release of $\mathrm{JO}$ in the initial hours and high tendency of $\mathrm{CdO}$ to lure mosquitoes for landing. $\mathrm{EO}$ and $\mathrm{CO}$ did not allow the mosquitoes to land and thus, deterred bites, despite the initial bites. Due to the quickest sublimation of $\mathrm{CO}$ from the cavities of $\beta$-CD CA, \% B was higher and thus, lower \% R. LO had allowed lesser \%B and thus, higher \% R and optimum repellent activity. $\mathrm{PO}$ was the one giving the highest $\% \mathrm{R}$ and lowest $\% \mathrm{~B}$ due to the highest $\%$ retention level after $6 \mathrm{~h}$ that might had helped to repel mosquitoes away from the cotton surface. $\mathrm{CdO}$ and $\mathrm{JO}$ had shown the highest and lowest \% $\mathrm{M}$ among all the Eos. Rest Eos had shown the intermediate levels of \%M in between $\mathrm{CdO}$ and JO. The preferential behavior of Eos towards arthropods was due to their respective compositions as monoterpenes and sesquiterpenes are the most active constituents of oils that reflect mosquito repellent activity. Monoterpenes are more volatile than the sesquiterpenes due to their molecular weight, thus 1,8 cineole (EO), linalool (LO), menthol (PO) and Eugenol (CO) are the most common monoterpenes that evaporated the fastest to give

Table 4 Post hoc analysis for mosquito repellence of ICs of Eos- $\beta-C D$ CA

\begin{tabular}{|c|c|c|c|c|c|c|}
\hline Oil type & $\mathrm{CdO}$ & $\mathrm{CO}$ & EO & PO & LO & JO \\
\hline$\% M$ & $50 \pm 3.2^{\mathrm{a*}}$ & $44 \pm 2.0^{a, b *}$ & $40 \pm 3.2^{\mathrm{a}, \mathrm{c} *}$ & $33 \pm 2.0^{a, b, c, c d *}$ & $21 \pm 0.0^{a, b, c, d, e * *}$ & $12 \pm 2.3^{a, b, c, d, e}$ \\
\hline$\% R$ & $48.5 \pm 3.0^{\mathrm{a}}$ & $51.5 \pm 3.0^{b}$ & $60 \pm 3.46^{a, b, c}$ & $64.25 \pm 2.5^{a, b, d}$ & $55 \pm 2.3^{\mathrm{a}, \mathrm{d}, \mathrm{e}}$ & $39.5 \pm 2.89^{a, b, c, d, d, e}$ \\
\hline$\% B$ & $39 \pm 2.0^{\mathrm{a}}$ & $37 \pm 2.0^{b}$ & $30 \pm 2.3^{\mathrm{a}, \mathrm{b}, \mathrm{c}}$ & $27 \pm 2.0^{\mathrm{a}, \mathrm{b}, \mathrm{d}}$ & $35 \pm 2.0^{c, d, e}$ & $46 \pm 2.31^{a, b, c, d, e}$ \\
\hline
\end{tabular}

*Various super-indices, i.e. $a, b, c$, $d$ and e indicate statistical differences in repellence between the Eos ( $p<0.05$ ANOVA) and Tukey Kramer post hoc analysis. ${ }^{a}$ Statistical difference of $\mathrm{CdO}$ with other Eos, ${ }^{\mathrm{b}}$ Statistical difference of $\mathrm{CO}$ with other Eos, c Statistical difference of EO with other Eos, ${ }^{d}$ Statistical difference of PO with other Eos, and ${ }^{\mathrm{e}}$ Statistical difference of LO with other Eos 


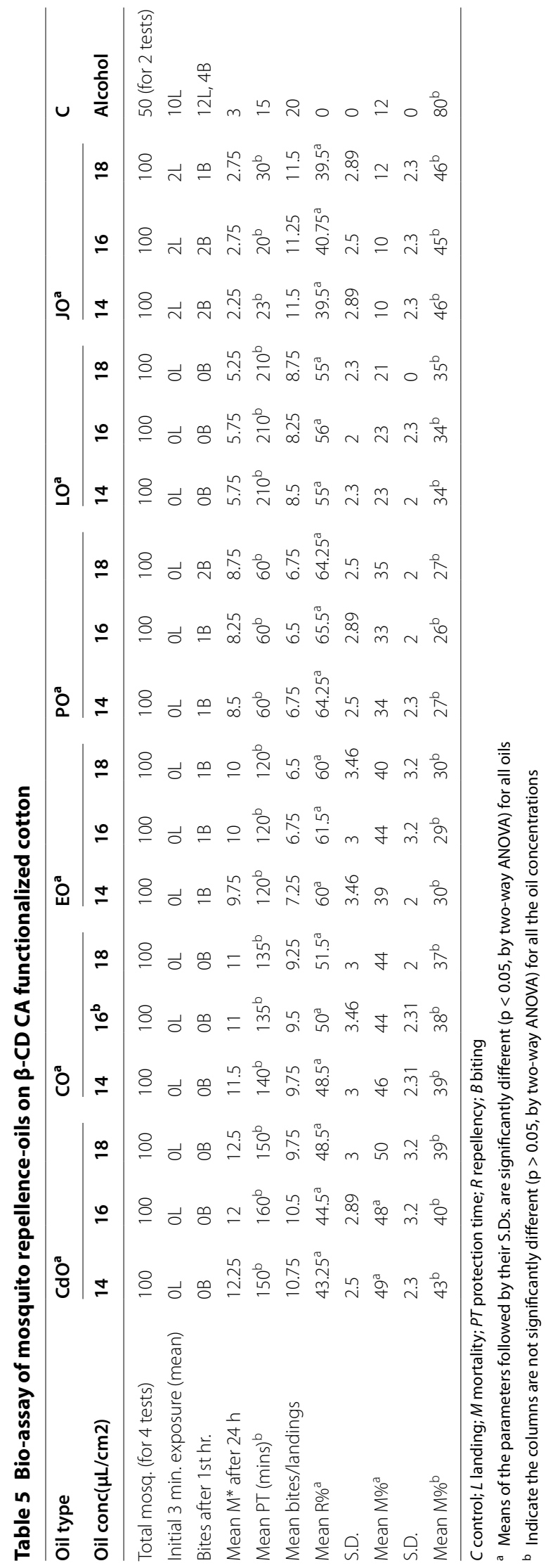




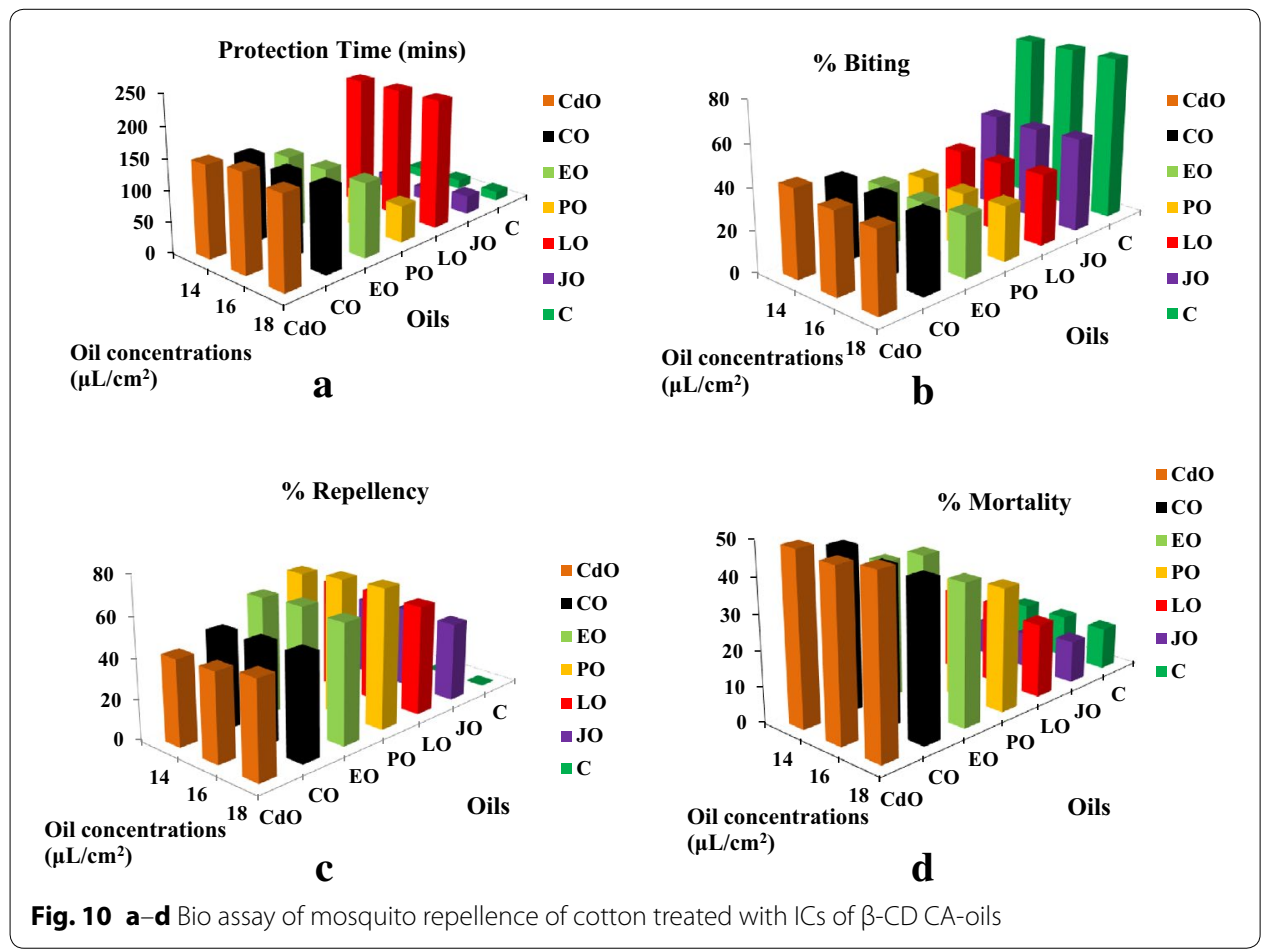

the quickest effect on the mosquitoes. On the other hand, oxygenated sesquiterpenes (as $\beta$-caryophyllene in $\mathrm{CdO}$ ) was the slowest to release thereby giving the sustained release.

\section{Conclusions}

The solubility of $\beta$-CD CA in water had shown a tremendous increase as compared to native $\beta$-CD. Interaction of $\beta$-CD CA concentration and curing temperature was most influential on graft yield, tensile strength, yellowness index and durability. ${ }^{1} \mathrm{H}-\mathrm{NMR}$ spectral analysis revealed only partial inclusion of Eos into cyclodextrin cavity except JO. The phenomenon of inclusion complexation exerted a thermo-chemical influence on treated cotton and altered its thermal behaviour. Oils of Jasmine is the weakest against mosquitoes as it worked as an attractant simulating flower nectar Eucalyptus and Clove are the feeding deterrents, Lavender and Peppermint are potential mosquito repellents and Cedarwood is an effective mosquito killer.

Authors' contributions

SK and JNC planned the work. SK carried out the work and drafted the manuscript. Both the authors read and approved the final manuscript.

Competing interests

The authors declare that they have no competing interests.

Ethics approval and consent to participate

Not applicable.

Publisher's Note

Springer Nature remains neutral with regard to jurisdictional claims in published maps and institutional affiliations. 


\section{References}

Abdel-Mohdy, F., Fouda, M. M. G., Rehan, M. F., \& Aly, A. S. (2008). Repellency of controlled-release treated cotton fabrics based on cypermethrin and prallethrin. Carbohydrate Polymers, 73(1), 92-97.

Abdel-Mohdy, F., Fouda, M. M. G., Rehan, M. F., \& Aly, A. S. (2009). Repellency of controlled-release treated-cotton fabrics based on permethrin and bioallethrin against mosquitoes. The Journal of The Textile Institute, 100(8), 695-701.

Aly, S. A., Hashem, A., \& Hussein, S. S. (2004). Utilization of chitosan citrate as crease-resistant and antimicrobial finishing agent for cotton fabric. Indian Journal of Fibre \& Textile Research, 29, 218-222.

Dehbadi, V. A., Buschmann, H. J., \& Gutmann, J. S. (2014). A novel approach for fixation of $\beta$-cyclodextrins on cotton fabrics. Journal of Inclusion Phenomena and Macrocyclic Chemistry, 79(3-4), 459-464. https://doi.org/10.1007/ s10847-013-0368-0.

Dong, C., Ye, Y., Qian, L., Zhao, G., He, B., \& Xiao, H. (2014). Antibacterial modification of cellulose fibres by grafting $\beta$-cyclodextrin and inclusion with ciprofloxacin. Cellulose, 21, 1921-1932.

El-Tahlawy, K., El-Nagar, K., \& Elhendawy, A. G. (2007). Cyclodextrin-4 Hydroxy benzophenone inclusion complex for UV protective cotton fabric. Journal of the Textile Institute, 98(5), 453-462.

El-Tahlawy, K., Gaffar, M. A., \& El-Rafie, S. (2006). Novel method for preparation of $\beta$-cyclodextrin/grafted chitosan and its application. Carbohydrate Polymers, 63, 385-392.

Fahmy, H. M. (2004). Enhancing some performance properties of ester crosslinked cotton fabric by pre-quaternization. Egyptian Journal of Chemistry, 47(6), 627-639.

Fouda, M. M. G., \& Fahmy, H. M. (2011). Multifunctional finish and cotton cellulose fabric. Carbohydrate Polymers, 86, 625-629.

Hebeish, A., El, Shafei A., \& Shaarawy, S. (2009). Synthesis and characterization of multifunctional cotton containing cyclodextrin and butylacrylate moieties. Polymer-Plastics Technology and Engineering, 48(8), 839-850.

Hebeish, A., Hamdy, I. A., El-Sawy, S., \& Abdel-Mohdy, F. A. (2010). Preparation of durable insect repellent cotton fabric through treatment with a finishing formulations containing cypermethrin. The Journal of The Textile Institute, 101(7), 627-634.

Hebeish, A., Hamdy, I. A., EL-Sawy, S. M., \& Fouda, M. M. G. (2008). Preparation of durable insect repellent cotton fabric: Limonene as insecticide. Carbohydrate Polymers, 74(2), 268-273.

Jantan I and Zaki Z M (1999). Development of environment-friendly insect repellents from the leaf oils of selected Malaysian plants'. ASEAN Review of biodiversity and environmental conservation (ARBEC), 1-7.

Karolia, A., \& Mendapara, P. (2005). Application of antimicrobial and fragrance finish in combination by microencapsulation on cotton. Journal of the Textile Association, 66(4), 155-159.

Kasprzyk W, Bednarz S and Bogdal D (2010). Sorption properties of $\beta$-Cyclodextrin- citric acid derivatives, 14th International electronic conference on synthetic Organic chemistry (ECSOC-14), 1-7.

Levya, E., Moctezuma, E., Strouse, J., \& Agaribay, M. A. G. (2001). Spectrometric and 2D NMR studies on the complexation of chlorophenols with cyclodextrins. Journal of Inclusion Phenomena and Macrocyclic Chemistry, 39, 41-46.

Martel, B., Morcellet, M., Ruffin, D., Vinet, F., \& Weltrowski, M. (2002a). Capture and controlled release of fragrances by CD finished textiles. Journal of Inclusion Phenomena and Macrocyclic Chemistry, 44, 439-442.

Martel, B., Weltrowski, M., Ruffin, D., \& Morcellet, M. (2002b). Polycarboxylic acids as crosslinking agents for grafting cyclodextrins onto cotton and wool fabrics: Study of the process parameters. Journal of Applied Polymer Science, 83(7), $1449-1456$.

Masetti, A., \& Maini, S. (2006). Arm in cage to compare skin repellents against bites of Aedes albopictus. Bulletin of Insectology, 59(2), 157-160.

Prabha, R., \& Vasugi, R. N. (2012). Filarial repellent finish using medicinal plants. Indian Journal Science, 1(1), 74-76.

Ramchandran, T. (2009). Optimization of process parameters for crease resistant finishing of cotton fabric using citric acid. Indian Journal of Fibre and Textile Research, 34, 359-367.

Romi, R., Nostro, P. L. O., Bocci, E., Ridi, F., \& Baglioni, P. (2005). Bioengineering of a cellulosic fabric for insecticide delivery via grafted cyclodextrin. Biotechnol Progress, 21, 1724-1730.

Samanta, A. K., Hossain, A., Bagchi, A., \& Bhattacharya, K. (2016). Simultaneous dyeing and fragrance finishing of cotton fabric. Journal Material Science \& Application, 2(4), 25-34.

Shahba, A. F., Osama, H., Mohamed, R., \& Mohamed, H. (2011). Development of Longer-Lasting insect repellence cellulosic based curtain fabrics. Material Science and Applications, 2(3), 200-208. https://doi.org/10.4236/msa.2011.23025.

Songkro, S. H. N., Jaisawang, J., Maneenuan, D., Chuchome, T., \& Kaewnopparat, N. (2012). Investigation of inclusion complexes of citronella oil, citronellal and citronellol with $\beta$-cyclodextrin for mosquito repellent. Journal of Inclusion Phenomena and Macrocyclic Chemistry, 72, 339-355.

Specos, M. M. M., Zannoni, V., Topollan, D., Arata, J., Vivod, V., Garcia, J., et al. (2013). Controlled release of mosquito repellents by cyclodextrins treated textiles. Istanbul: The International Istanbul Textile Congress.

Voncina, B., \& Marechal, A. M. L. (2005). Grafting of cotton with $\beta$-Cyclodextrin via poly (carboxylic Acid). Journal of Applied Polymer Science, 96, 1323-1328.

World Health Organization (2013), Guidelines for laboratory and field testing of long-lasting insecticidal nets, WHO/HTM/ NTD/WHOPES/2013.1, ISBN 9789241505277. 